\title{
Design of a Carding Machine Modern Main Cylinder
}

\author{
Piotr Danielczyk *, Jacek Stadnicki \\ University of Bielsko Biala, Departament of Engineering Fundamentals, ul. Willowa 2, 43-309 Bielsko-Biala
}

\section{BIOGRAPHICAL NOTES}

Piotr Danielczyk Ph.D. works as a lecturer in the Department of Mechanical Engineering Fundamentals at University of Bielsko-Biala. His scientific and didactic work concerns the issues of machine dynamics, computer-aided design, application of the Finite Element Method in engineering calculations and, engineering methods of optimization. He is the author or co-author of 46 articles and papers prepared for conferences including 3 in ISI Master Journal List.

Jacek Stadnicki, Prof. Ph.D. D.Sc works as a professor in the Department of Mechanical Engineering Fundamentals at University of Bielsko-Biala. His scientific and didactic work concerns the issues of machine designing and technology, computer aided engineering, optimization, Finite Element Method, dynamic of machines, textile machinery. He is the author or co-author of 89 original scientific papers including: 2 monographs, 7 papers published in scientific journals in ISI Master Journal List, 41 papers published in foreign journals magazines and 4 patents. Since 2008 he has been the Dean of Mechanical Engineering and Computer Science faculty of University in Bielsko-Biała.

\section{KEY WORDS}

Carding machine, main cylinder, optimization, Finite Element Method.

\section{ABSTRACT}

The following paper presents the design of a modern main cylinder in the carding machine with a special bottom with a conical ring. In order to find the optimum dimensions of the cylinder, considering the criterion of minimal deflection, parametric FEM model of the cylinder developed in the ANSYS package has been used. Polak-Ribery conjugate gradient method has been applied for searching the optimal solution. As a result of the performed analyses, reduction of maximum deflection value at approximately $80 \%$ has been obtained. Optimal cylinder dimensions enable application of a new textile technology - microfibre carding and improvement in the quality of traditional carding technology of woolen and wool-like fibres.

\section{Introduction}

Carding is a textile process where fibres of appropriate length are strengthened and parallelised, rubbish and short fibres gathered in the web are removed. Next, they are formed into a semi-finished product in the form of a thin layer of fibres with the width of the machine - web or sliver which is formed by condensing the web. Woolen and wool-like fibres are reworked with the use of roller carding machines [4]. Their scheme is shown in Figure 1.

On the surfaces of the main cylinder - swift, the doffer and working rollers (workers and strippers) there are teeth of a saw metallic wire or card clothing needles which are reeled coil to coil with appropriate tension. Fed by feeding rollers and licker-in (the first 


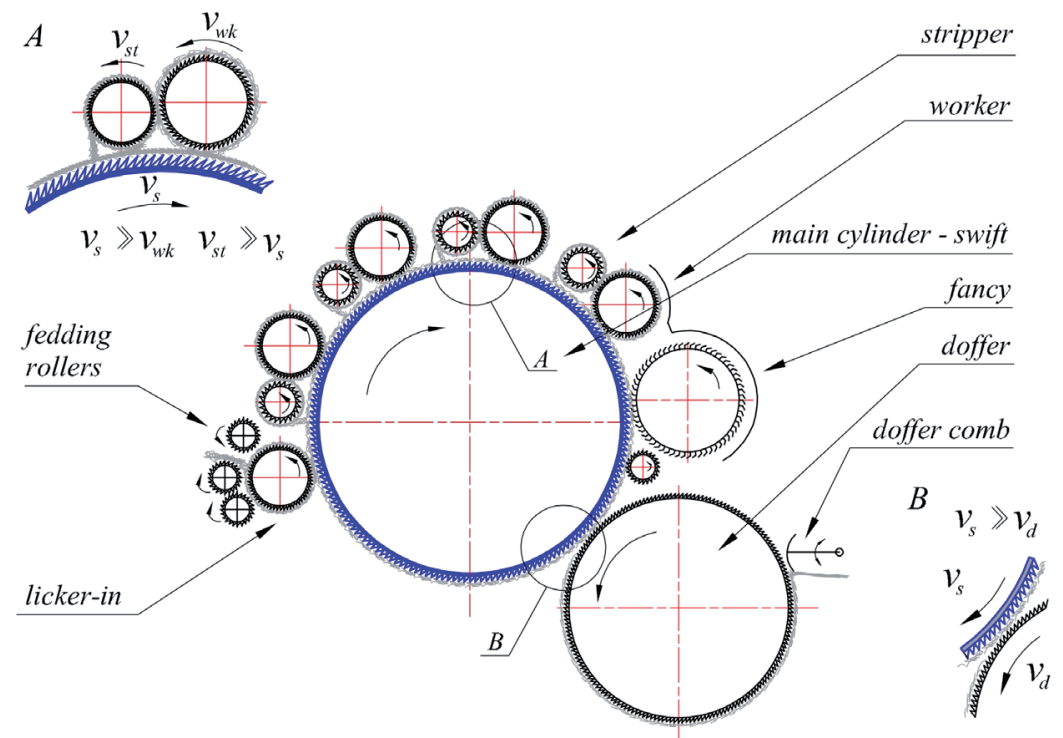

Fig. 1: Scheme of the carding machine

carding machine in carding set) and the common roller (the following carding machines in carding set), the fibres are taken over by the swift teeth and carried to the other pairs of rollers worker-stripper. Thanks to the large difference of tangential velocities of the swift $v_{s}$ and the worker $v_{w k}\left(v_{s} \gg v_{w k}\right)$ and the small distance between them, their teeth separate, comb and straighten the carried fibres. The stripper whose tangential velocity $\nu_{s t}$ is greater than the tangential velocity of the worker $\left(v_{s t}\right)$ $\left.v_{w k}\right)$, feeds back a part of fibres for another carding. The process is repeated between the cylinder and the following pairs of rollers worker-stripper. However, the distance between the swift and next workers decreases. Finally, a roller rotating at high speed - fancy $\left(\nu_{f} \gg v_{s}\right)$ with long bent needles lifts the fibres above the teeth of the swift which carries them further condensing them on the teeth of the slowly rotating doffer $\left(v_{d}\right)$ because $v_{s} \gg v_{d}$. If the carding machine is the last machine in the carding set, the oscillating blade (doffer comb) combs and condenses the fibres after carding, forming the web.

\section{The Design and Requirements of Cylinders in Modern Carding Machines}

Since the nineties of the last century, thanks to the research described, among others, in [1], carding machines have been equipped with cylinders with internal ring-like reinforcements. These rein- forcements would ensure the required stiffness of the whole cylinder, both during work and during its manufacturing (grinding the surface with the disk-type grinding wheel before reeling the metallic card wire). The design of a typical working cylinder made by BEFAMA SA is shown in Figure 2a. It consists of a shell reeled of sheet metal welded along its edges, cast wheel hubs, the shaft and reinforcement rings. This solution has been successfully used in manufactured carding units. Currently, mainly for technological reasons, cylinders are closed with bottoms welded from sheet metal with ribs which are easier to make (Fig.2b), and the solutions offered by leading carding machine manufacturers and particular solutions are different from the construction of bottom and reinforcement rings.

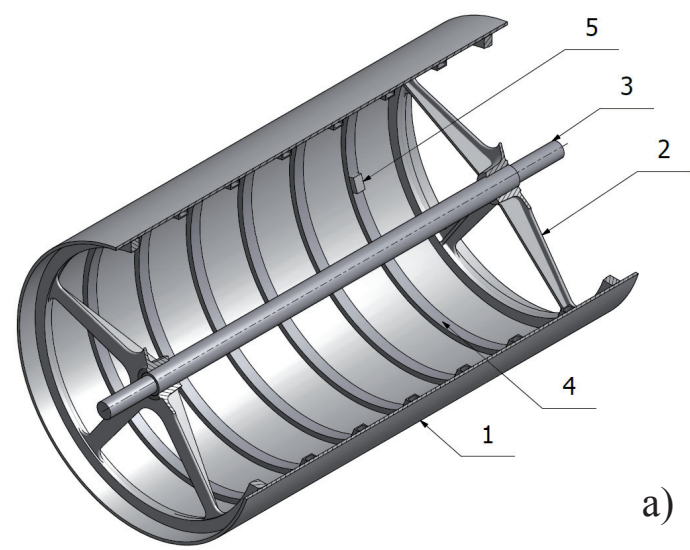




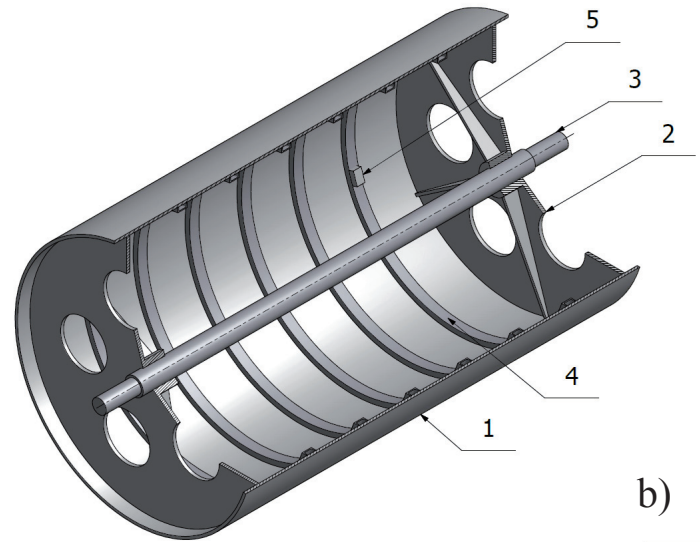

Fig. 2: a) cylinder with cast wheel hubs, b) cylinder with welded bottoms: (1) shell, (2) cast wheel hubs/ bottoms, (3) shaft, (4) reinforcement ring, (5) balancing slug.

Carding quality depends to a large degree on the height and shape of the gap between the swift and the worker and between the swift and the doffer. When carding thin fibres, the gap height is between 0.3 and $0.15 \mathrm{~mm}$, and considering desirable uniformity of the web, its shape should be close to the shape of a rectangle. Taking into account the durability of the metallic card wire teeth (hardness of a tooth is decreasing from top to base), the cylinder should not be ground after the wire has been reeled as long as it is sharp enough. Therefore, the swift should be designed in such a way so that after reeling the metallic card wire on it at tension, the amplitude of deflection $\Delta$ of the shell does not exceed several hundredths of a millimetre (Fig.3).

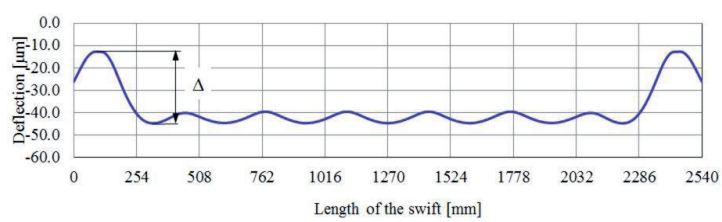

Fig. 3: The deflection line of the example cylinder.

Taking into account its dimensions (diameter $x$ length: the main cylinder $\varnothing 1500 \mathrm{~mm} \times 2500 \mathrm{~mm}$, the doffer $\varnothing 1270 \mathrm{~mm} \times 2500 \mathrm{~mm}$ ), and the wall thickness usually between 10 and $14 \mathrm{~mm}$, the requirements as to the construction stiffness are very high. It is essential to bear in mind that increasing the shell thickness, which directly leads to decrease in the amplitude of deflection, increases the cost and the mass of the cylinder. Moreover, it makes the mass moment of inertia bigger which in turn causes problems with starting the machine and imposes the necessity of using special brakes for stopping the cylinder in the required time in case of a breakdown.

Therefore, work was undertaken to develop the design of a cylinder with the most favorable parameters, particularly useful for carding fine fibers. For this purpose, a discrete calculation model of a cylinder was built with the use of the FEM.

\section{FEM Model of the Cylinder}

The discrete calculation model of the cylinder with a flat side hub (compare Fig. 2b) was made in ANSYS package [8] using Shell $\mathbf{6 3}$ elements (shell and bottoms and its ribs) and Beam 188 elements (rings and shaft). Shell $\mathbf{6 3}$ is a four-node shell element with six degrees of freedom in each node three translations and three rotations, which takes into account the membrane and bending state of the shell. Beam $\mathbf{1 8 8}$ is a two-node beam element which is consistent with Timoshenko beam theory. During the process of shaft discretization, it was ensured that the nodes were located in places where there are self-aligning rolling bearings supporting the cylinder. Hinged support on the right side (the side where the belt transmission driving the cylinder is placed) and the roller support on the left side were applied in the nodes.
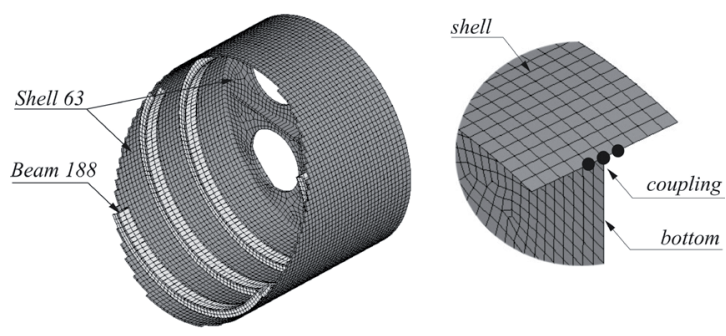

Fig. 4: FEM model of the cylinder (part).

Due to the fact that in real constructions the side hub circumference is permanently fixed to the shell, the shell nodes which lie on the side hub surface and the adjacent nodes on the left and right side were coupled, ensuring the compatibility of node values (translations and rotations).

All analyses were performed with the use of input files for ANSYS programme. Using the Ansys Parametric Design Language, a parametric FEM model of the analysed construction was written and the optimization task formulated. It is worth 
to emphasize that the input file prepared in this way enables fast analysis and optimization of cylinder constructions for various working widths and constructional forms (e.g. with any number of reinforcement rings).

\section{Loads Acting on the Main Cylinder of Carding Machine}

The loads acting on the cylinder result from:

- the influence of fibres on the teeth of card wire during the carding process, the forces are small [4] and are omitted when calculating deflection of the cylinder shell,

- the construction dead weight and centrifugal force; their influence on the cylinder deflection may also be neglected due to big stiffness of cylinder shell and small rotational speed of the cylinder (circa 100 $\div 200$ rpm) [3],

- reeling at tension of the metallic card wire.

Reeling at tension $S$ and the reeling pitch $t$ of the card wire on the cylinder with the radius $\mathrm{R}$ (Fig.5a) causes pressure on the cylinder shell directed radially inward with the value of

$p_{r}=\frac{S}{t R}$

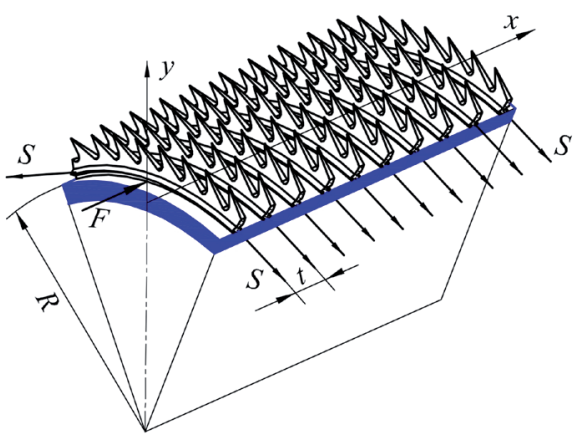

a)

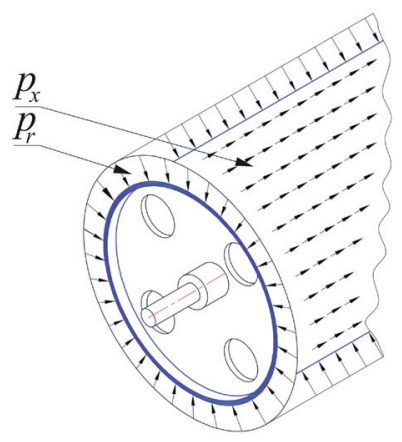

b)

Fig. 5: (a) Tension forces acting on the metallic card wire coils, (b) Load scheme
As shown in paper [3], taking into account only radial pressure $\boldsymbol{p}_{\boldsymbol{r}}$ in calculations of the cylinder shell deflection does not give sufficient compatibility of calculation results and experimental measurements. When reeling the metallic card wire at tension $\boldsymbol{S}$, the coils are pressed against each other with the force $\boldsymbol{F}$ acting in the direction of cylinder axis and the so called side wire which is the stopper ring (see Fig 5b). After reeling all coils, the last coil rests against the side wire on the opposite side of the cylinder. One may say that the cylinder shell is reeled with "foil of metallic card wire" hich is initially tensioned and acts on the cylinder in radial direction with pressure $\boldsymbol{p}_{\boldsymbol{r}}$ and in axial direction with surface force $\boldsymbol{p}_{\boldsymbol{x}}$ which is the result of residual friction forces between the metallic card wire and the cylinder shell. The value of surface force $\boldsymbol{p}_{\boldsymbol{x}}$ is expressed by the following equation:

$p_{x}=\mu p_{r}$

where: $\mu$-coefficient of static friction between the saw wire flange and the cylinder surface.

The authors of the paper [3] proved that taking into account both the pressure $\boldsymbol{p}_{\boldsymbol{r}}$ as well as the surface force $\boldsymbol{p}_{\boldsymbol{x}}$ when calculating the deflection of the cylinder shell, gives sufficient compatibility of calculations with experimental tests. Axisymmetrical radial surface pressure $\boldsymbol{p}_{\boldsymbol{r}}$ and pressure acting in the direction of the cylinder axis $\boldsymbol{p}_{\boldsymbol{x}}$ were applied to the cylinder shell. The pressure values were assumed on the basis of [6] as equal to $\boldsymbol{p}_{\mathbf{r}}=220 \mathrm{kPa}$ and $\boldsymbol{p}_{\boldsymbol{x}}=33 \mathrm{kPa}$.

\section{Calculation results}

As a result of the discrete model analysis of the cylinder with flat bottoms, a graph of deflection line has been obtained (Fig. 6). The value of deflection amplitude is $\Delta \cong 36 \mu m$. It is worth to mention that taking into consideration pressure $\boldsymbol{p}_{\boldsymbol{x}}$ results in the line of shell deflection not being symmetric.

As can be seen in Fig. 6, the amplitude of deflection of the cylinder shell is determined by the difference in stiffnesses of the bottom and the shell with ribs. For the reasons described above, increasing the stiffness of the shell itself leads to an unacceptable increase in the wall thickness. Therefore, the only way to decrease the amplitude of deflection is to redesign the bottom. A special form of the bottom with a conical ring (Fig. 7) which is charac 
terized by flexibility in the radial and axial direction has been suggested and which at the same time ensures stable fixing of the cylinder during subsequent processing steps as well as during work.

The most preferred method of bottom arrangement in the cylinder has been selected by performing a number of auxiliary numerical tests. The dimensions of the cylinder with conical bottoms have been found by solving an appropriate optimization task with the use of the discrete calculation model of the cylinder prepared in a similar way as described in paragraph 2.
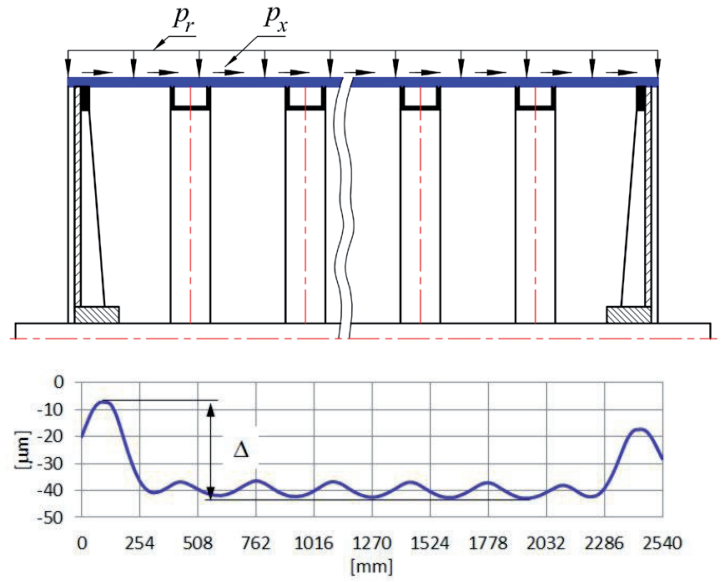

Fig. 6: The scheme of the cylinder and the deflection line with flat bottoms.

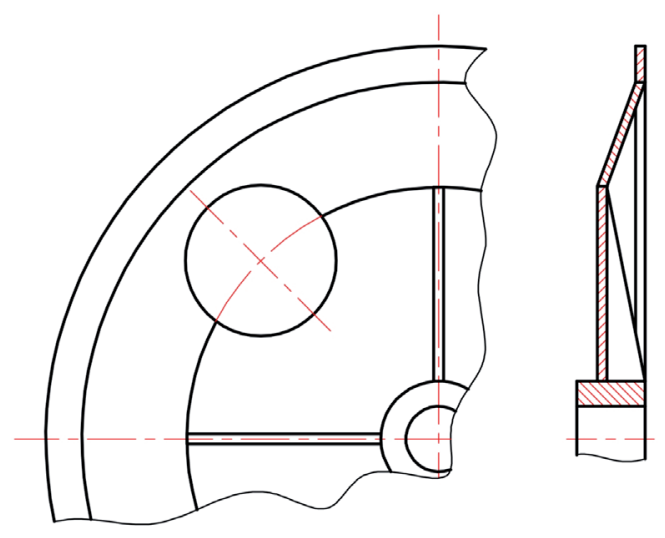

Fig. 7: Changed construction of the bottom with conical ring.

\section{Optimization Task}

In order to determine optimal dimensions of the cylinder with bottom presented in Fig. 8, the following optimization task has been solved:

- decision variables (Fig. 10): thickness of the shell and the side hub $g_{1}$, the distance between the wheel $\boldsymbol{g}_{2}$ hub and the first reinforcement ring $\boldsymbol{b}$, dimension c which characteristic of the side hub form, dimensions of the reinforcement cross-section: $\boldsymbol{h}, \boldsymbol{s}, \boldsymbol{t}$,

- objective function: deflection amplitude of the cylinder shell $\Delta \rightarrow$ min. (see Fig. 3),

\section{- limitations.}

the mass of the construction with optimal di mensions should not exceed the mass of the initial construction: $\hat{m} \leq m_{0}$

- maximum reduced stresses in the construc tion cannot be bigger than permissible stress es for constructional steel S235JR: $k_{r}=120 \mathrm{MPa}$

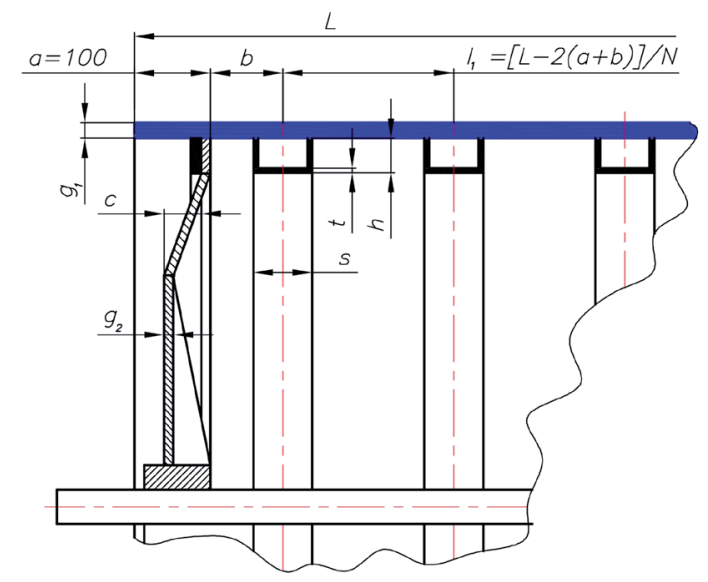

Fig. 8: Denotations of decision variables in optimization task.

Moreover, appropriate variation ranges for decision variables have been introduced for the task. The ranges resulted from, among other things, technological conditions such as: difficulties in proper manufacturing of the shell by reeling a flat sheet of steel with the width of over $14 \mathrm{~mm}$, as well as boundary dimensions of a section of reinforcement rings resulting from the technology of reeling the ring and the availability of the semifinished product. In order to solve the task, a PolakRibery conjugate gradient method has been used together with the interior penalty method [5].

As a result of solving the above-mentioned optimization task, optimal values of decision variables $\hat{g}_{1} / \hat{g}_{2}=10 / 14 \mathrm{~mm}, \hat{b}=298 \mathrm{~mm}, \hat{c}=27 \mathrm{~mm}, \hat{h} / \hat{s} / \hat{t}=$ $=35 / 24 / 4.4 \mathrm{~mm}$ have been obtained. The mass of the optimal construction is equal to its mass before optimization and is $\hat{m}=1635 \mathrm{~kg}$, the deflection amplitude is $\Delta=6.2 \mu \mathrm{m}$ (Fig.9). 

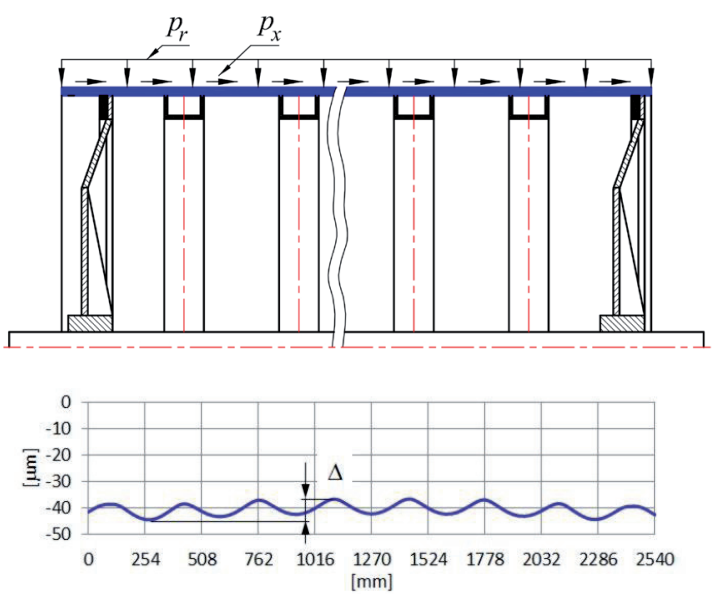

Fig. 9: The scheme of the cylinder and the deflection line for the optimal configuration.

The Figure 10 shows the deflection of the cylinder shell in radial direction for the initial construction and the optimal construction. A more favourable distribution of deflections on cylinder shell is noticed for optimal construction.

a)
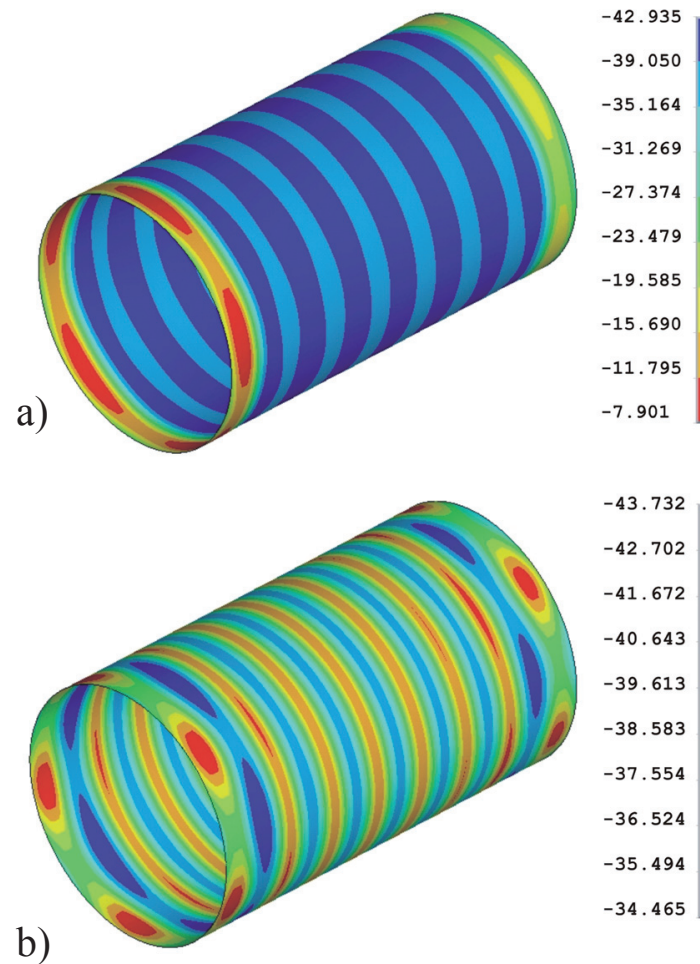

$-43.732$

$-42.702$

$-41.672$

$-40.643$

$-39.613$

$-38.583$

$-37.554$

$-36.524$

$-35.494$

$-34.465$

\section{Conclusion}

The following article presents work which aims at improving the quality of carding machine working cylinders. The improved construction of bottoms with a conical ring was suggested (Fig. 7). Solving an appropriate optimization task and basing on a discrete calculation model of the cylinder, construction form has been obtained ensuring a significant about 78\% decrease of the deflection amplitude to the value of $\Delta \cong 8 \mu m$ (see Fig. 6 and Fig. 9), as compared with constructions with flat bottoms. The result is a uniformity of gaps between working rollers and the main cylinder as well as between the doffer and the main cylinder without increasing the construction mass and its mass moment of inertia in relation to the axis of rotation. It is worth adding that the amplitude of deflection of the shell with bottoms and a conical ring and dimensions which are the solution of optimization problem formulated in 5 does not exceed cylinder manufacturing tolerance (radial run-out of the cylinder shell is $\pm 10 \mu \mathrm{m})$ and metallic card wire manufacturing tolerance (on the average $\pm 10 \mu \mathrm{m}$ ).

\section{References and Notes}

[1] Stadnicki, J., 1997, Optimal Design of the Cylindrical Shell of a Card Machine. Textile Research Journal, 67(1): 6-10

[2] Stadnicki J., Danielczyk P., 2003, Optimization of construction of doffing comb device considering decrease of doffing blade amplitudes, Acta Mechanica Slovaca, rocnik 7, $4 b$

[3] Stadnicki, J., Wróbel, I., 2003, Practical Engineering Calculation for Working Cylinders of Carding Machines, Textile Research Journal, 73(6): 525-529

[4] Lawrence, CA., 2003, Fundamentals of spun yarn technology, CRC Press

[5] Bazaraa, M.S., Sherali, H.D., Shetty, C.M., 2006, Nonlinear programming: theory and algorithms. John Willey \& Sons

[6] Wróbel, I.,2002, Influence of selected features of a carding machine working cylinder on the shell deflection: PhD Thesis, University of Bielsko-Biala, Poland

[7] EN 10025-1:2004. Hot Rolled Products Of Structural Steels - Part 1: General Technical Delivery Conditions.

[8] Ansys Help SYSTEM, 2008.

Fig. 10: (a) initial shell deflection [ $\mu \mathrm{m}]$, (b) optimal shell deflection $[\mu \mathrm{m}]$ 